\title{
Translation and Psychometric Evaluation of the Persian Version of Lupus Erythematosus Quality of Life Questionnaire (LEQoL)
}

Seyed Majid Ahmadi

Yasuj University of Medical Sciences

Zeinab Rezaie

Kashan University of Medical Sciences

Seyed Mojtaba Ahmadi

Kermanshah University of Medical Sciences

\section{Sajad Raisi}

Kermanshah University of Medical Sciences

Mohammadreza Davoudi ( $\nabla$ davoudi.phd.psy@gmail.com )

University of Social Welfare and Rehabilitation Science https://orcid.org/0000-0003-0352-0290

\section{Research}

Keywords: Psychometric, Lupus Erythematosus, Autoimmune Diseases, cutaneous, Quality of life

Posted Date: May 4th, 2021

DOI: https://doi.org/10.21203/rs.3.rs-436424/v1

License: (c) (1) This work is licensed under a Creative Commons Attribution 4.0 International License. Read Full License 


\section{Abstract}

Background: Recently a comprehensive and multi-diversionary scale for assessing Quality of Life (QoL) in Patients with Lupus has been developed. This study aimed to evaluation psychometric properties of the Persian version of Lupus Erythematosus Quality of Life Questionnaire (LEQoL) in Iranian patients with Lupus Erythematosus.

Method: We used the forward-backward translation, and cognitive interview for linguistic translation. A cross-sectional design was utilized. We recruited a convenience sample of 165 lupus patients aged 19 years or over from the Iranian social media and Tehran city rheumatology clinics. Patients completed the 36-Item Short Form Survey (SF-36), The Symptom Checklist-90-R (SCL-90-R), and the translated LEQoL. The psychometric properties of the LEQoL were examined to establish test-retest reliability, internal consistency with Cronbach's alpha coefficient (COA), divergent-convergent validity, and construct validity. Also, we used Confirmatory factor analysis (CFA) and exploratory factor analysis (EFA) for assessing factor structures.

Results: The total COA was $a=0.86$. All subscales internal consistency ranging from $0.85-0.94$. The findings of test-retest reliability for the overall scale was 0.93 and the subscales ranging between $0.82-$ 0.92 . The results from a CFA indicated that goodness-of-fit are satisfactory $(\chi 2 / d f=1.28, R M S E A=$ $0.042, \mathrm{CFI}=0.975)$. Also EFA showed that the Persian version of LEQoL with five-factor can explain $73.7 \%$ of the variances. For assessing validity, every factor of LEQoL has a correlation with some SF.36 and SCL-90-R subscales. This matrix indicates that the LEQoL subscales are somewhat independent, and this matter is one strength issue. Only depression (SCL-90 subscale) has a significant correlation with all LEQoL subscales.

Conclusion: The translated Persian version of the LEQoL is a suitable scale for assessing QoL in Iranian patients with lupus.

\section{Introduction}

One of the chronic, heterogeneous, inflammatory, and autoimmune disease with broad dimensions of symptoms is Lupus Erythematosus (LE)(1). LE characterized by immune dysregulation, production of autoantibodies, damages in various organs (e.g. Skin and the brain). LE divided in two main subsets: lupus erythematosus (SLE) and cutaneous lupus erythematosus (CLE) (2). The lupus erythematosus and cutaneous lupus erythematosus can occur co-morbid and separately(3). The prevalence of LE is at least five million worldwide, and the result showed that the prevalence of SLE in Iran is estimated at 40 per 100,000 Iranian(3). About gender differences, in every 10 LE patients, nine of them are female(4).

In chronic diseases context, one of the therapeutic aim is enhancing quality of life. As interventions for treating LE are in first steps, so one of the primary and important therapeutic aims for these patients is increasing their quality of life (5-7).The scientific literature showed that many psychiatric and neuropsychiatric symptoms can occur in LE patients. These symptoms include mood changes, chorea, 
seizures, anxiety, suicide, sleep disturbance, cognitive dysfunction, and even psychotic (8-10). So, this disease has bio-psycho-social nature and patient's quality of life is multidimensional (e.g. emotional and physical). For assessing LE quality of life, there are some tools such as Lupus Quality of Life (Lupus QoL)(11), Systemic Lupus Erythematosus Quality of Life Questionnaire (L-QoL) (12), and Skindex to measure dermatology(13). These scales showed promising results in English patients and used widely. However, this scale has various and important limitation. First, these scales did not assess LE in general. In fact, they evaluate skin pathology, systemic lupus erythematosus, or other subsets instead of all domains. Second, as mentioned above QoL has various dimensions (emotional, physical, Cognition, Interpersonal, and Appearance), But, theses scales only evaluating one or two QoL-related dimensions(13). Finally, it is also suggested that a holistic point of view can describe patients in a comprehensive way and expand the clinician's attention regarding making treatments. $(12,13)$.

Recently, a Lupus Erythematosus Quality of Life Questionnaire (LEQoL) has been developed by Castellano-Rioja et.al (2020). This scale measures Lupus Erythematosus patient's Quality of Life in five subscale: Physical Factor, Appearance factor, Emotional factors, Cognition factor, and Relationship factor(14).

This scale tried to eliminate the limitations that exist in other similar scales. In fact, it is a multifactorial tool that examines the quality of life in a wide range of patients' problems. It also has a holistic view of the physical injuries and physical activities of patients. Finally, this tool is not only for SLE and is used for all LE patients. To be placed. Therefore, the aim of the present study was to investigate the psychometric properties of the Persian version of LEQoL in the Iranian population with SLE.

\section{Materials And Methods}

\section{Study design}

This Cross-sectional translation and psychometric evaluation of the Persian version of Lupus Erythematosus Quality of Life Questionnaire (LEQoL) was conducted in 2021 at the Department of Clinical psychology, Kermanshah University of Medical Sciences (KUMS). Permission was obtained from Giménez-Espert (corresponding author of the original version of scale).

\section{Study population}

A cross-sectional study was done with a convenience sample. Participants included 172 patients with LE from Iran. From these 172 patients, 165 patients met the inclusion criteria for the study: diagnosed as systemic or cutaneous/discoid lupus erythematosus, and motivated to take participating in research" were included. All 165 patients were over 18 years old and signed an informed consent form. The data collection process occurred in March to April 2021.

\section{Linguistic validation}


The linguistic validation of the LEQoL from Spanish to Persian consisted of three steps: a forward translation, a backward translation, and cognitive interviews. Two independent, bilingual Persian-native speakers with medical backgrounds (psychologists) translated the original Spanish version into Persian. A consensus version was developed by discussion and revision of the translated versions by the authors. Backward translation of the consensus version was performed independently by one Spanish native speaker without a psychological background, who was familiar with the culture of the Spanish and translated language. Adequacy of the translated version was proven by comparison of the original with the backward-translated versions. Next, the patient examination was conducted. The personal interviews were conducted during which the interviewer asked whether the participant had any trouble in understanding the LEQoL and checked the participant's interpretation of all items. Finally, proofreading was performed $(15,16)$.

\section{Procedures}

Initially a battery of tests including the Persian version of LEQoL, Symptom Checklist-90-R (SCL-90), and 36-Item Short Form Survey (SF-36). These tools were used to check validity. Then a Google Form containing all the mentioned questionnaires was created. Then a public announcement was spread to the Iranian population through the social networks Instagram and Telegram. Due to the low prevalence of LE, the notice asked individuals to call or send a message or send information or notifications if they have or know a person with lupus. The corresponding author of the article also referred to rheumatology clinics in Tehran (the capital of Iran, the most populous city in Iran) and asked clients to participate in this study. Finally, people with lupus were interviewed for 20 minutes. Regarding inclusion criteria, 165 people were included in the study. Then, the tools were provided to these people online and they were asked to send them to the researchers as soon as they completed them. The information will be collected confidentially and anonymously and the results will not be shared with others.

\section{Instrument}

Quality of Life of Patients with Lupus Erythematosus Instrument” (LEQoL): This scale consist of 21 items in five subscales: Physical Factor, Appearance factor, Emotional factors, Cognition factor, and Relationship factor. Results showed that original version of LEQoL has suitable psychometric properties(14). The higher scores indicate higher impairments in patients with Lupus. In this research we tried to assess psychometric properties of the Persian version of LEQoL.

Psychological symptoms: To evaluate the psychological symptoms of the patients, the SCL-90-R (Symptom Checklist-90-R) was utilized. The SCL-90-R evaluates the current level of the symptoms which occur during the last seven days. The aim of this scale is to carry out a brief evaluation of the type and severity of the patient's symptoms by self-assessment and has eight subscales, besides a total score (Sleeping Problems, Sensitivity, Anxiety, Depression, Obsessive-Compulsive, Somatization, Agoraphobia, and Hostility). We used the Persian manual for examining the SCL-90 data. Item scores range from zero (none) to four (severe). Cronbach's alpha's for the Iranian SCL-90 was 0.90(17). 
General Quality of Life: For assessing the general quality of life in participants we used 36 Items Short Form Survey (SF-36). This scale consists of 36 items classified into eight subscales: role impairment due to physical health/role physical (4 items), mental health (5 items), energy and fatigue/vitality (4 questions), physical functioning (10 questions), social functioning (2 questions), general health (5 questions), body pain ( 2 items), and role impairment due to emotional health/role emotional (3 items). Two other general subscales are obtained by combining the subscales known as Mental Component Summary (MCS), and Physical Component Summary (PCS). In this scale, high scores described as higher levels of QoL, and vice versa. Psychometric researches showed that the Persian version of SF-36 has suitable validity and reliability in the Iranian population(18).

\section{Statistical analysis}

Data have been analyzed by SPSS V. 25 and AMOS 26 software's. In order to analyze the data using descriptive statistics (mean, standard deviation, frequency and percentage) as well as Cronbach's alpha method to assess internal consistency, the correlation of LEQoL with SF-36 and SCL-90 were used to assess convergent validity. Also, test-retest reliability (from 25 participants) with two week was assessed by intraclass correlation coefficient (ICC). Confirmatory factor analysis (CFA) was used to examine the adequacy of the resulting factor model. To assess model fit, this research utilized a range of incremental and absolute model fit indices, including the ratio of chi-square to degrees of freedom (X2/df), root mean square error of approximation (RMSEA),comparative fit index (CFI), The goodness of fit index (GFI), and S-BX2 (df). Exploratory factor analysis (EFA) was applied to examine instrument dimensionality. KaiserMeyer Olkin measure of sampling adequacy (KMO) and Bartlett's test of sphericity were analyzed first to determine the suitability of the data to undergo factor analysis.

\section{Results}

\section{Sample characteristics}

The Iranian patients with lupus diagnosis $(n=165)$ had a mean age of $40.49 \pm 13$ (range 19 to 65 ) years. Near eleven percent $(n=17)$ were male, and $71.5 \%(n=118)$ had suffered systemic lupus. Table 1 showed a comprehensive picture about Participants' sociodemographic and clinical characteristics. 
Table 1

Participants' sociodemographic and clinical characteristics $(n=165)$

\begin{tabular}{|c|c|c|}
\hline Variable & & Mean \pm SD / N (\%) \\
\hline \multirow[t]{2}{*}{ Gender } & Male & $17(10.3 \%)$ \\
\hline & female & $148(89.7 \%)$ \\
\hline \multirow[t]{3}{*}{ Education level } & Under diploma & $73(44.2 \%)$ \\
\hline & Diploma & $62(37.6 \%)$ \\
\hline & University graduated & $30(18.2 \%)$ \\
\hline Age & & $40.49 \pm 13$ \\
\hline \multirow[t]{2}{*}{ Lupus erythematosus type } & Cutaneous & $47(28.5 \%)$ \\
\hline & Systemic & 118(71.5\%) \\
\hline \multirow[t]{3}{*}{ Time to diagnosis } & Less than six months & $25(15.2 \%)$ \\
\hline & Six to twelve months & $34(20.6 \%)$ \\
\hline & More than one year & $106(64.2 \%)$ \\
\hline \multirow[t]{4}{*}{ Marital status } & Single & $23(13.9 \%)$ \\
\hline & Married & $104(63 \%)$ \\
\hline & In a relationship & $9(5.5 \%)$ \\
\hline & Other status/ prefer not to say & $29(17.5 \%)$ \\
\hline
\end{tabular}

\section{Internal Consistency}

The Cronbach's a value for the Persian version of the LEQoL was measured at 0.862 , which implies satisfactory internal consistency. Table 2 showed that all items if removed (except 18th item), lead to decrease the value of alpha, which means that items are appropriate. The various dimensions showed alpha values of between 0.85 and 0.94 (Physical Factor $a=0.88$, Appearance factor $a=0.85$, Emotional factors $a=0.93$, Cognition factor $a=0.85$, Relationship factor $a=0.94$ ). 
Table 2

Item-Total Statistics

\begin{tabular}{|c|c|c|c|c|}
\hline Items & $\begin{array}{l}\text { Scale Mean if } \\
\text { Item Deleted }\end{array}$ & $\begin{array}{l}\text { Scale Variance if } \\
\text { Item Deleted }\end{array}$ & $\begin{array}{l}\text { Corrected Item-Total } \\
\text { Correlation }\end{array}$ & $\begin{array}{l}\text { Cronbach's Alpha if } \\
\text { Item Deleted }\end{array}$ \\
\hline LEQoL1 & 91.5939 & 457.011 & .586 & .851 \\
\hline LEQoL2 & 91.6121 & 466.849 & .507 & .854 \\
\hline LEQoL3 & 91.9030 & 471.295 & .428 & .857 \\
\hline LEQoL4 & 91.6909 & 469.020 & .451 & .856 \\
\hline LEQoL5 & 91.8303 & 466.312 & .440 & .856 \\
\hline LEQoL6 & 91.6364 & 461.794 & .538 & .853 \\
\hline LEQoL7 & 91.3636 & 459.452 & .438 & .857 \\
\hline LEQoL8 & 91.3818 & 452.579 & .539 & .853 \\
\hline LEQoL9 & 91.4909 & 465.386 & .453 & .856 \\
\hline LEQoL10 & 91.5333 & 458.214 & .504 & .854 \\
\hline LEQoL11 & 91.7879 & 463.863 & .432 & .857 \\
\hline LEQoL12 & 91.3152 & 466.778 & .416 & .857 \\
\hline LEQoL13 & 91.2000 & 462.478 & .474 & .855 \\
\hline LEQoL14 & 91.3697 & 460.966 & .529 & .853 \\
\hline LEQoL15 & 91.2606 & 461.182 & .502 & .854 \\
\hline LEQoL16 & 91.6485 & 483.266 & .256 & .863 \\
\hline LEQoL17 & 91.6545 & 475.520 & .374 & .859 \\
\hline LEQoL18 & 91.7212 & 485.910 & .257 & .863 \\
\hline LEQoL19 & 91.8545 & 474.015 & .404 & .858 \\
\hline LEQoL20 & 91.8061 & 473.974 & .410 & .858 \\
\hline LEQoL21 & 91.7394 & 475.877 & .395 & .858 \\
\hline
\end{tabular}

\section{Test Retest Reliability}

To test-retest reliability evaluation, the 30 patients were chosen by the computer version of the random number table. They completed the scale a second time two weeks after the baseline assessment without being presented the scale they had previously filled out. The test-retest reliability coefficient was found to be 0.964 for the whole scale (Lower Bound: 0.925, Upper Bound: 0.983) and this measure was significant 
in 0.01 significance level $(P<0.01)$. This measure indicate that this scale has strong test re-test reliability and is suitable for interventional studies.

\section{Validity}

In order to investigate the validity, the correlation between the LEQoL, SCL-90-R and SF-36were calculated. As shown in Table 3, some convergent-divergent correlations are significant at the 0.01 level. Therefore, LEQoL and its subscales have appropriate Validity levels.

Table 3. Pearson's coefficient correlations among variables

\begin{tabular}{|c|c|c|c|c|c|c|c|c|c|c|c|c|c|c|c|c|c|c|c|c|c|}
\hline 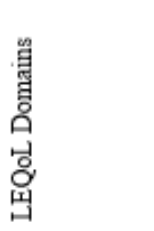 & 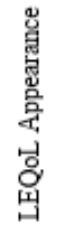 & $\begin{array}{l}\text { 范 } \\
\text { 总 } \\
\text { 嵒 } \\
\text { 㟔 } \\
\text { 岧 }\end{array}$ & 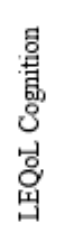 & 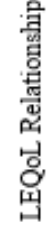 & 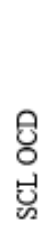 & $\begin{array}{l}\text { 吾 } \\
\text { 鄫 } \\
\text { 鄫 } \\
\text { 恖 }\end{array}$ & 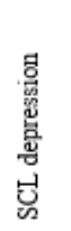 & 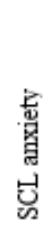 & 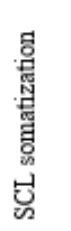 & 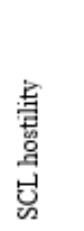 & $\begin{array}{l}\text { 总 } \\
\text { 总 } \\
\text { 矛 }\end{array}$ & 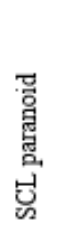 & 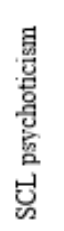 & 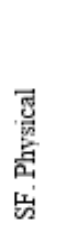 & 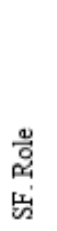 & $\begin{array}{l}\text { 䍇 } \\
\text { 䋆 }\end{array}$ & $\begin{array}{l}\text { 离 } \\
\text { 量 } \\
\text { 岁 }\end{array}$ & 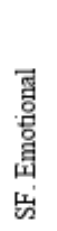 & $\begin{array}{l}\text { 丞 } \\
\text { ڤ } \\
\text { 山' }\end{array}$ & $\begin{array}{l}\text { 罟 } \\
\text { 凱 }\end{array}$ & 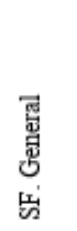 \\
\hline physical & 0.3 & .18 & $\begin{array}{r}0.1 \\
4\end{array}$ & .21 & .25 & .23 & .31 & .31 & .26 & .09 & -.02 & -.04 & 0.0 & -19 & -.01 & -.18 & -.01 & -.1 & -.07 & -.08 & -.25 \\
\hline Appearance & 1 & $\begin{array}{r}0.2 \\
2\end{array}$ & $\frac{0.1}{\underline{85}}$ & $\frac{0.1}{7}$ & $\begin{array}{l}\underline{0.1} \\
\underline{66}\end{array}$ & 0.165 & 0.25 & $\begin{array}{r}0.2 \\
8\end{array}$ & 0.2 & 0.18 & -.02 & 0.2 & -.01 & -.03 & - &.- .19 & - 233 & -.07 &.- .179 & 0.54 & -182 \\
\hline Emotional & & 1 & .1 & $\begin{array}{r}0.2 \\
3\end{array}$ & $\begin{array}{r}0.1 \\
3\end{array}$ & 0.16 & 0.21 & $\begin{array}{r}0.2 \\
8\end{array}$ & 0.004 & 0.155 & -.04 & 0.0 & .07 & .07 & .07 & -30 & -32 & 0.41 & -.03 & .05 & -196 \\
\hline Cognition & & & 1 & .08 & .02 & .06 & .16 & .05 & .18 & .18 & .14 & -.05 & .07 & -.33 & .06 & -.2 & -.17 & .202 & -.03 & -.1 & -.229 \\
\hline Relationship & & & & 1 & .21 & .334 & .26 & .15 & .06 & .28 & -.03 & -.06 & .02 & -.01 & -.02 & $\begin{array}{r}= \\
.187\end{array}$ & -.11 & $\begin{array}{r}- \\
.175 \\
\end{array}$ & -.27 & 0.00 & 0.1 \\
\hline
\end{tabular}

SCL: SCL-90-R, OCD: obsessive-compulsive disorder, interpersonal: interpersonal sensitivity, phobic phobic anxiety, physical: Physical functioning, Role: Role limitations due to physical health, EP: Role limitations due to emotional problems, Emotional: Emotional well-being, Social: Social functioning, General: General health

Bolded correlations indicate the correlation is significant at the 0.01 level (2-tailed).

Underlined correlations indicate the correlation is significant at the 0.05 level (2-tailed).

\section{Exploratory Factor Analysis (EFA)}

The responses of patients (165) were utilized for the evaluation of the EFA of CSS. KMO test showed strong sampling adequacy (0.828). Bartlett's Test was significant (chi-square value $=2175.647, \mathrm{P}$-value $<$ 0.001 ) that explained the items are correlated and factor analysis can be fitted. Latent factors were achieved by the principal components analysis. The extracted factors were rotated with the varimax way. This criterion suggested the five-factor, which explained $73.7 \%$ of the variance (Table $4 \&$ Fig. 1 ). The pattern matrix of extracted factors is shown in Table 5. 
Table 4

Extracted principal components with Eigenvalues, Cumulative percentage of explained variance

\begin{tabular}{|llll|}
\hline Component & Initial solution & Rotated solution \\
\cline { 2 - 4 } & $\begin{array}{l}\text { Cumulative \% of variance } \\
\text { explained }\end{array}$ & Eigenvalue & $\begin{array}{l}\text { Cumulative \% of variance } \\
\text { explained }\end{array}$ \\
\hline 1 & 27.468 & 27.468 & 18.469 \\
\hline 2 & 14.095 & 41.562 & 34.707 \\
\hline 3 & 11.749 & 53.312 & 49.782 \\
\hline 5 & 10.549 & 63.861 & 62.657 \\
\hline
\end{tabular}


Table 4

Pattern matrix of scale

\begin{tabular}{|c|c|c|c|c|c|}
\hline & Comp & nent & & & \\
\hline & 1 & 2 & 3 & 4 & 5 \\
\hline LEQoL1 & .807 & & & & \\
\hline LEQoL2 & .786 & & & & \\
\hline LEQoL3 & .758 & & & & \\
\hline LEQoL4 & .768 & & & & \\
\hline LEQoL5 & .816 & & & & \\
\hline LEQoL6 & .766 & & & & \\
\hline LEQoL7 & & & .810 & & \\
\hline LEQoL8 & & & .781 & & \\
\hline LEQoL9 & & & .745 & & \\
\hline LEQoL10 & & & .744 & & \\
\hline LEQoL11 & & & .783 & & \\
\hline LEQoL12 & & .913 & & & \\
\hline LEQoL13 & & .921 & & & \\
\hline LEQoL14 & & .899 & & & \\
\hline LEQoL15 & & .879 & & & \\
\hline LEQoL16 & & & & & .889 \\
\hline LEQoL17 & & & & & .876 \\
\hline LEQoL18 & & & & & .842 \\
\hline LEQoL19 & & & & .927 & \\
\hline LEQoL20 & & & & .922 & \\
\hline LEQoL21 & & & & .941 & \\
\hline $\begin{array}{l}\text { Extraction } \\
\text { Rotation N }\end{array}$ & $\begin{array}{l}\text { ethod: } \\
\text { thod: V }\end{array}$ & $\begin{array}{l}\text { rincip } \\
\text { imax }\end{array}$ & $\begin{array}{l}\text { Comp } \\
\text { h Kai }\end{array}$ & $\begin{array}{l}\text { ent An } \\
\text { Norm }\end{array}$ & $\begin{array}{l}\text { is. } \\
\text { ation. }\end{array}$ \\
\hline a. Rotation & onverg & $d$ in 5 & ation & & \\
\hline
\end{tabular}


To confirm the latent structure of CSS, the CFA was evaluated. The analysis was carried out on the whole sample $(n=160)$. Factor solution with two to five factors was modelled to check if the 5 -factor is the best. Indicators of models were shown in Table 5. RMSEA and parsimony goodness of fit index (PGFI) for the 5 -factor model are smaller than other models and CFI is larger. Also, the model has the best indexes that show the five-factor extracted model is the best representation of the structure of the data. Figure 2 showed the best model fit for five-factor solution.

Table 5

indicators to five-factor model about model fitness

\begin{tabular}{|lllll|}
\hline No. of factors & $\chi 2 / \mathrm{df}$ & $\mathrm{CFI}$ & Robust RMSEA (90\% Cl) & PGFI \\
\hline 5 factors & 1.28 & 0.975 & $0.042(0.0240 .057)$ & 0.692 \\
\hline
\end{tabular}

\section{Discussion}

The present paper aimed to translate and evaluate the psychometric properties of the Persian version of the LEQoL. As individuals with lupus are reportedly suffering from psychosocial and physical limitations due to their symptoms, it is important to adequately measure QoL to assess the effects of interventional researches. The present study found to support that a 21 -item Persian version of LEQoL could be used to assess QoL in individuals who have lupus.

The procedure of forward-back translation was executed fluently in this investigation. Regarding the reliability of the scale, the total Cronbach's alpha coefficient had very well qualifies $(a=0.86)$, which was similar to the values in the original Spanish version $(a=0.92)$. All give subscales also had good and excellent internal consistency (ranging from 0.85-0.94, which was consistent with the original Spanish version (ranging from 0.82-0.92). Moreover, the findings of test-retest reliability for the overall scale (ICC $=0.93$ ) and the five subscales (ranging between 0.82-0.92) indicated that the LEQoL possesses good stability over time, which was consistent with the original Spanish version.

In this research, the results from a CFA on data from 165 patients with lupus indicated that the psychometric properties of the LEQoL questionnaire are satisfactory. Specifically, most of the values used to evaluate the goodness-of-fit are satisfactory $(X 2 / d f=1.28, \mathrm{RMSEA}=0.042, \mathrm{CFI}=0.975)$. Also, for $E F A$ results showed that for Persian version of LEQoL with five-factor can explain $73.7 \%$ of the variances which is almost equal with the original scale EFA with $75.3 \%$.

Moreover, we used divergent-convergent correlations for assessing validity. We found that every factor of LEQoL has correlation with some SF.36 and SCL-90-R subscales. This matrix indicate that the LEQoL subscales are somewhat independent, and this matter is one strength issue. Only depression (SCL-90 subscale) has significant correlation with LEQoL subscales which means the common problem for every LEQoL factor is depression and clinicians must pay attention to this issue for all patients with lupus. This result is in accordance with pervious researches. The research literature showed that every reduction in 
QoL has strong correlation with depression incidence. In fact, depression and QoL can affect each other(19-21).

Besides existing other scales for assessing QoL in patients with lupus, this scale is multi-diversionary, and brief. Brief scales with adequate subscales and self-referred nature are more suitable rather than comprehensive, difficult, and unclear scales $(14,22)$. In Iran, because of poor insurance procedures and lack of an adequate number of clinicians all around the country, brief and clear scales can help patients to use self-assessment. Also, these scales can help clinicians to obtain a comprehensive view of patients' quality of life in a short time.

The current research besides important strengths has a number of limitations. First, the study is limited by the prevalent limitations in psychological research, including using voluntary participation and selfreport scales. Second, notwithstanding the sufficiency of the sample size, it may not nationally representative (Iran consists of various cultures and lifestyles). Third, for the validity assessment of the LEQoL, we used convergent and construct (only confirmatory factor analysis) validity. Totally, future researches can evaluate other types of construct validity such as predictive, and discriminant. Also, future research can develop family-reported and clinician-reported of this scale.

\section{Conclusion}

The translated Persian version of the LEQoL scale used in this research is a reliable and consistent tool that showed suitable internal consistency and validity. Clinicians can assess Qol in patients with lupus by this scale, and following patients' progress during treatment. Also, researchers can assess their intervention efficacy by using this scale. Finally, the patients and their families can use LEQoL as a selfreported measure for a better understanding of their disease.

\section{Abbreviations}

EFA: Exploratory factor analysis, CFA: Confirmatory factor analysis, GFI: Goodness-of-fit index, AGFI: Adjusted goodness of fit index, CFI: Comparative fit index RMSEA: Root mean square error of approximation SRMR: Standardized root mean square residual, QoL: Quality of Life, LEQoL: Lupus Erythematosus Quality of Life Questionnaire.

\section{Declarations}

\section{Acknowledgements:}

The authors wish to thanks all participants for their assistance and participation in this study.

\section{Funding:}

None. 


\section{Competing interests:}

The authors does not have any competing interests to declare.

\section{Ethics approval and consent to participate:}

All procedures used in collecting survey data on which this article relies on, are in accordance with the ethical standards of the Helsinki Declaration of 1964 and subsequent amendments or ethical standards. All data were collected anonymously, and no association could be established between the questionnaires and the responders.

\section{Availability of data and materials:}

Data are available upon reasonable request from the researchers.

\section{Contributions:}

M.D and S.M.A (Majid) have made substantial contributions to conception and design. S.R and Z.R collecting date. S.M.A (Mojtaba) analyzing data and drafting result subsection. All author take participate in Drafting the manuscript. Then, First author and corresponding author revised and submitted manuscript.

\section{References}

1. Pamuk ON, Hasni S. Correspondence on 'Blood-brain barrier leakage in systemic lupus erythematosus is associated with gray matter loss and cognitive impairment'. Annals of the rheumatic diseases. 2021.

2. Charras A, Smith E, Hedrich CM. Systemic Lupus Erythematosus in Children and Young People. Current rheumatology reports. 2021;23(3):20.

3. Akbarian M, Faezi ST, Gharibdoost F, Shahram F, Nadji A, Jamshidi AR, et al. The epidemiology of systemic lupus erythematosus in Iran: a survey on 2143 cases. Tehran University Medical Journal. 2010;68(5).

4. Singh JA, Shah NP, Mudano AS. Belimumab for systemic lupus erythematosus. The Cochrane database of systematic reviews. 2021;2:Cd010668.

5. Seguier J, Jouve E, Bobot M, Whalen E, Dussol B, Gentile S, et al. Paradoxical association between blood modular interferon signatures and quality of life in patients with systemic lupus erythematosus. Rheumatology (Oxford, England). 2020;59(8):1975-83.

6. Kusnanto K, Sari N, Harmayetty H, Efendi F, Gunawan J. Self-care model application to improve selfcare agency, self-care activities, and quality of life in patients with systemic lupus erythematosus. Journal of Taibah University Medical Sciences. 2018;13(5):472-8. 
7. Applyrs DL, Williams EM, Faith TD, Kamen DL, Vazques E, Jurkowski JM. Cultural and quality-of-life considerations when administering corticosteroids as a therapeutic strategy for African American women living with systemic lupus erythematosus. Patient preference and adherence. 2018;12:100714.

8. Huang HC, Liu CM, Liu CC. Psychiatric manifestations in systemic lupus erythematosus mimic psychotic prodrome: a case report. General hospital psychiatry. 2010;32(2):e3-4.

9. Eldeiry D, Zandy M, Tayer-Shifman OE, Kwan A, Marzouk S, Su J, et al. Association between depression and anxiety with skin and musculoskeletal clinical phenotypes in systemic lupus erythematosus. Rheumatology (Oxford, England). 2020;59(11):3211-20.

10. lacobas D, Wen J, lacobas S, Schwartz N, Putterman C. Remodeling of Neurotransmission, Chemokine, and PI3K-AKT Signaling Genomic Fabrics in Neuropsychiatric Systemic Lupus Erythematosus. Genes. 2021;12(2).

11. McElhone $\mathrm{K}$, Abbott J, Teh LS. A review of health related quality of life in systemic lupus erythematosus. Lupus. 2006;15(10):633-43.

12. Doward LC, McKenna SP, Whalley D, Tennant A, Griffiths B, Emery P, et al. The development of the LQoL: a quality-of-life instrument specific to systemic lupus erythematosus. Annals of the rheumatic diseases. 2009;68(2):196-200.

13. Chren M-M, Lasek RJ, Flocke SA, Zyzanski SJ. Improved Discriminative and Evaluative Capability of a Refined Version of Skindex, a Quality-of-Life Instrument for Patients With Skin Diseases. Archives of Dermatology. 1997;133(11):1433-40.

14. Castellano-Rioja E, Giménez-Espert MdC, Soto-Rubio A. Lupus Erythematosus Quality of Life Questionnaire (LEQoL): Development and Psychometric Properties. International Journal of Environmental Research and Public Health. 2020;17(22):8642.

15. Cooper HE, Camic PM, Long DL, Panter A, Rindskopf DE, Sher KJ. APA handbook of research methods in psychology, Vol 1: Foundations, planning, measures, and psychometrics: American Psychological Association; 2012.

16. Miles J, Gilbert P. A handbook of research methods for clinical and health psychology: Oxford University Press on Demand; 2005.

17. Ardakani A, Seghatoleslam T, Habil H, Jameei F, Rashid R, Zahirodin A, et al. Construct validity of symptom checklist-90-revised (SCL-90-R) and general health questionnaire-28 (GHQ-28) in patients with drug addiction and diabetes, and normal population. Iranian journal of public health. 2016;45(4):451.

18. Montazeri A, Goshtasebi A, Vahdaninia M, Gandek B. The Short Form Health Survey (SF-36): translation and validation study of the Iranian version. Quality of life research. 2005;14(3):875-82.

19. Hunt SM, McKenna SP. The QLDS: a scale for the measurement of quality of life in depression. Health policy. 1992;22(3):307-19.

20. Katschnig H, Jaidhauser K, Subasi B, Zoghlami A, Serim M. Quality of life in depression. European Psychiatry. 1997;12(S2):116s-s. 
21. Ay-Woan P, Sarah CP, Lylnn C, Tsyr-Jang C, Ping-Chuan H. Quality of life in depression: predictive models. Quality of life research. 2006;15(1):39-48.

22. Paniagua FA, Yamada A-M. Handbook of multicultural mental health: Assessment and treatment of diverse populations: Academic Press; 2013.

Figures

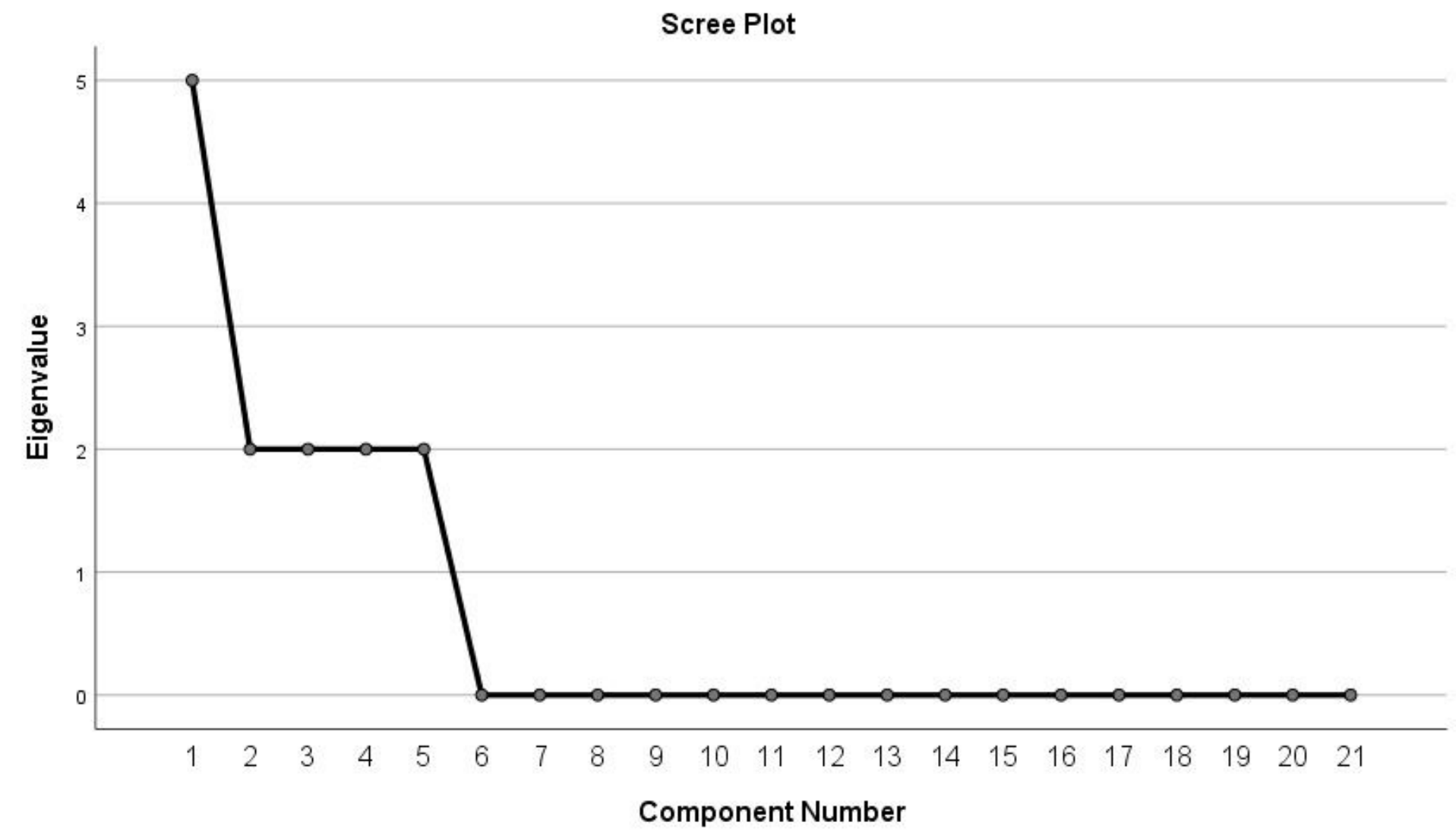

Figure 1

scree plot to five factors extracted by EFA with eigenvalues larger than 1 


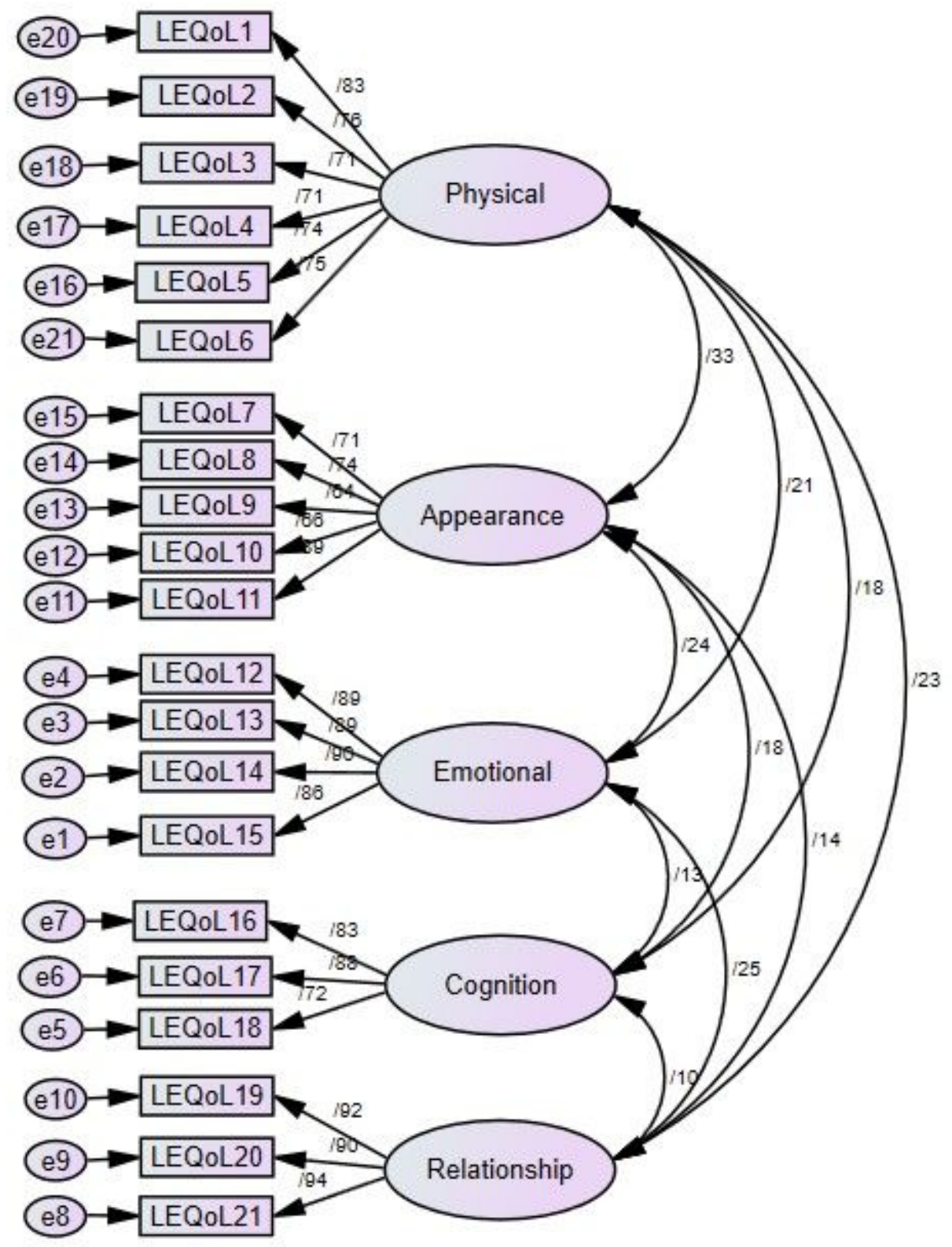

Figure 2

The best model fit for five-factor solution, the standardized parameter estimate 